Marquette University

e-Publications@Marquette

Economics Faculty Research and Publications

Economics, Department of

$7-1-2015$

\title{
Geographic Mobility and the Costs of Job Loss
}

Nicholas A. Jolly

Marquette University, nicholas.jolly@marquette.edu

Published version. B.E. Journal of Economic Analysis and Policy, Vol. 15, No. 4 (July 2015):

1793-1829. DOI. (C) 2015 Walter De Gruyter. Used with permission. 


\section{Contributions}

\section{Nicholas A. Jolly* \\ Geographic Mobility and the Costs of Job Loss}

DOI 10.1515/bejeap-2014-0131

Published online July 21, 2015

Abstract: This paper uses data from the 1968 through 1997 survey waves of the Panel Study of Income Dynamics to analyze how the long-term costs of job loss vary by a worker's post-displacement migration status. Results from the analysis show that those individuals who move within the first 2 years after a job loss experience lower earnings losses, lower reductions in hours worked, and smaller increases in time unemployed when compared to a group of displaced workers who are not geographically mobile during the early years following this life event. Workers who move within the first 2 years after displacement face a lower probability of homeownership when compared to their non-mobile counterparts. However, this lower probability is short-lived.

Keywords: job displacement, geographic mobility, costs of job loss

\section{Introduction}

Researchers and policy makers understand that job displacement is a large negative shock to workers' earnings and income. On average, displaced individuals experience a drop in earnings, amounting to $20-30 \%$ around the year of job loss (Ruhm 1991; Jacobson, LaLonde, and Sullivan 1993; Stevens 1997; Couch and Placzek 2010). These losses persist over time, averaging 10-15\% even 6 years after the event occurs. Lost earnings are significantly larger during poor economic conditions (Couch, Jolly, and Placzek 2011). When individuals experience such large, negative, persistent shocks, it is reasonable to expect that they adjust in some way. Given the number of public programs designed to assist displaced workers, an understanding of how individuals adjust to this type of job loss is important for policy purposes.

*Corresponding author: Nicholas A. Jolly, Department of Economics, College of Business Administration, Marquette University, P.O. Box 1881, Milwaukee, WI 53201-1881, USA, E-mail: nicholas.jolly@marquette.edu 
One way workers can adjust to displacement is by extending their job search across multiple locations. An area that has received little attention in the literature is how the use of geographic mobility can alter potentially the costs to individuals who experience this particular life event. This paper uses data from the 1968 to 1997 survey waves of the Panel Study of Income Dynamics (PSID) to investigate how post-displacement outcomes (earnings, hours worked, and time unemployed) vary depending upon whether or not workers move within a short time after separation. The analysis also examines the relationship between migration and displaced workers' earnings, hours worked, and time unemployed by tracking these outcomes over time around the date of the first post-displacement move. Since migration requires purchasing a new home or renting a new apartment, the analysis also examines mobile displaced workers' homeownership probabilities and compares them with their non-mobile counterparts' probabilities.

It is not clear how migration alters the costs associated with job loss. On the one hand, mobility may help dislocated workers. By extending the job search across multiple labor markets, displaced workers may gain access to a broader array of potential employment opportunities, thus reducing the duration of unemployment (Yankow 2004). Having more opportunities also implies that workers can be more selective with their choice of reemployment. If workers are more selective, then mobility may serve to increase the match quality with the firm, which mitigates one of the reasons Fallick (1996) provides for sustained earnings losses (Yankow 2004). ${ }^{1}$ A high-quality match with a new employer may also lower the probability of future job loss. Stevens (1997) shows that displaced workers who avoid multiple job losses fare significantly better than those who do not. Additionally, by searching for employment across multiple locations, displaced workers increase the probability of finding reemployment within their pre-displacement industry or occupation, thus reducing the loss of industry- or occupation-specific human capital (Boman 2011). Carrington (1993) and Neal (1995) note the importance for post-job loss recovery of obtaining reemployment within the pre-displacement industry.

Results from the Gibbons and Katz (1991) asymmetric information model may also imply that geographic mobility helps workers recover from job loss. In the model, employers have discretion over which employees to lay off. Laid-off workers are viewed by potential employers as being of low ability. These potential employers then offer these workers low wages on their subsequent

1 Fallick (1996) notes four reasons as to why these workers experience sustained losses to their labor earnings - loss of job- or industry-specific human capital; loss of a high-quality match between the worker and the firm; loss of industry or union wage premiums; and loss of seniority. 
jobs. Workers displaced through plant closures do not send this negative productivity signal to future employers since the previous firm has no discretion over whom to let go. This model implies that workers displaced through plant closures experience smaller earnings losses and lower unemployment durations than those displaced through layoffs. Gibbons and Katz (1991) provide empirical results in support of their model.

If potential employers have incomplete information, then migration may serve to hide the poor-productivity signal attached to a laid-off worker since he may be able to frame the job separation as being caused by something other than a layoff. Furthermore, the geographically distant potential employer could assume that the separation was voluntary and caused by the move itself. ${ }^{2}$ This discussion implies that laid-off workers who migrate may fare better than those who do not. It is not clear if migration would help laid-off workers more or less than those displaced through plant closures. Workers displaced by plant closures do not have to hide a low-productivity signal. However, Gibbons and Katz (1991) note that those displaced through plant closures reside in areas that are relatively more economically depressed when compared to laid-off workers. Therefore, while migration does not hide a low-productivity signal for workers displaced through plant closures, it may allow workers access to better labor markets.

On the other hand, geographic migration may not be beneficial for displaced workers, and individuals who move after job loss may fare worse than those who do not and who are able to find reemployment in their local area. Workers considering a move face uncertainty regarding their potential location of residence, particularly if the new location is geographically distant from where they currently reside. Moving requires considerable investments in information (Addison and Portugal 1987). Workers may obtain either low quality information, or not enough information on the labor market conditions characterizing their potential location of residence. If reemployment opportunities are not as abundant as originally thought, then unemployment duration may increase. Additionally, workers who migrate may lose their job search network, particularly if the move is geographically distant. This could further complicate the search process and increase unemployment duration. Finally, both a lack of information and loss of job search network may induce return migration to the original location of residence, which could increase unemployment duration.

2 It is important to note that Gibbons and Katz (1991) assume that plant closures are verifiable, which eliminates the possibility that laid-off workers could state that the displacement was caused by plant closure. Furthermore, the authors assume that any potential employee's claims regarding past or current employment is also verifiable. 
The increases in unemployment duration may decrease reservation wages and increase the likelihood of lower earnings upon reemployment.

Additionally, those who move may be self-selected (Gustafson 1998; Yankow 2004; Boman 2011). Migrating workers may be of high ability when compared to non-movers. However, self-selection could be negative in the case of displaced individuals. Those who move after job loss may be of low ability and face difficulties finding reemployment within their local labor markets (Yankow 2004; Boman 2011). They only extend their job search across locations once they have investigated and exhausted any local reemployment opportunities. This process may increase unemployment duration and lower reservation wages, which again increases the probability of lower earnings upon reemployment. Therefore, even when considering self-selection, it is not clear how the costs of displacement vary by mobility status.

Given the above discussion, there is no a priori reason to expect that individuals who migrate after job loss experience better or worse outcomes than those who do not. The methodology used here includes individual fixed effects in the estimated equations (in addition to conducting a series of robustness checks) to analyze how the costs of job loss vary by post-separation migration status. Including individual fixed-effects accounts for any time-invariant, unobserved heterogeneity that may be correlated with the observed regressors, the probability of moving, and the probability of experiencing a displacement. ${ }^{3}$ To the extent that selectivity bias remains in the estimated parameters, the results still describe the inter-temporal relationship between migration and various labor market outcomes associated with displacement.

Results from the analysis should be helpful for public policy. One particular program designed to aid displaced workers is the Trade Adjustment Assistance (TAA) Act. Two benefits available from TAA are job search and relocation allowances (US Department of Labor). ${ }^{4}$ Job search allowances reimburse 90\% of the costs involved in travel and subsistence for those individuals searching for reemployment outside of their "normal commuting area," with a maximum benefit of $\$ 1,250$. Relocation allowances reimburse $90 \%$ of the expenses involved in moving to a location outside of the "normal commuting area" once a worker has found reemployment. Furthermore, under the relocation allowance, workers may qualify for a wage subsidy equal to three times their

3 While there are other methods available to account for selection, the use of individual fixed effects is common in the migration literature, which has used linear, individual fixed-effects models to study migration's effect on income (Pekkala 2002), male earnings (Rodgers and Rodgers 2000), and the earnings of women and the gender pay gap (Cooke et al. 2009).

4 The provision of these allowances varies from state to state. 
average weekly wage, with a maximum benefit of $\$ 1,250$. If programs such as these are to be designed effectively and efficiently, then it is important to understand the potential relationship between migration and post-displacement outcomes.

\section{Previous Literature}

Boman (2011) notes how much of the early displacement literature does not focus on geographic mobility explicitly. Instead, articles that mention this type of adjustment mechanism include an indicator for whether or not an individual moves as an explanatory variable in the estimated equations. Addison and Portugal (1987) find that migration tends to increase significantly displaced workers' unemployment duration; Nord and Ting (1991; 1992) note that migration increases the probability of experiencing positive weeks of unemployment. Addison and Portugal (1987) and Nord and Ting (1991) suggest that incomplete information concerning the post-migration location may increase search time and, therefore, unemployment duration.

Herzog and Schlottmann (1995) find that job-related migration has no discernable impact on the probability of reemployment. The authors mention that displaced workers who move may be relocating from poor local labor markets where the probability of reemployment was low. Therefore, if migrating workers had remained in their original labor market, then their probability of reemployment would have been lower. ${ }^{5}$ Nord and Ting $(1991,1992)$ present results showing that migration has no statistical impact on earnings losses. Given these early results, there does not appear to be consistent evidence regarding how postdisplacement migration influences the costs of job loss.

One potential reason for the differences between the results from these early studies is that they do not use panel data to track individuals over time. These studies' data come from the Displaced Worker Survey (DWS), which is a biennial supplement to the Current Population Survey. If individuals make decisions based upon their stream of lifetime earnings, then a cross-sectional dataset may not provide a long enough period for capturing any consistent positive or negative effects from migration (Boman 2011). Another potential reason is that these early studies do not account for any selection into migration. ${ }^{6}$ Those

5 Herzog and Schlottmann (1995) mention how their finding is consistent with a number of other studies.

6 Nord and Ting $(1991,1992)$ do account for selection into reemployment. 
individuals who decide to migrate may be self-selected, either positively or negatively (Gustafson 1998; Yankow 2004; Boman 2011). Not accounting for potential selection may cause differences in results.

Yankow (2004) uses data from the National Longitudinal Survey of Youth 1979 (NLSY79) and investigates whether local employment conditions matter for displaced workers' search strategies. Using a competing-risks hazards model, the author finds that strong local labor market conditions (high employment growth, high average wages, and low unemployment) are associated with displaced workers being more likely to find reemployment locally. However, low employment and low average wages are associated with an increased probability of displaced workers migrating to another location for reemployment.

Gustafson (1998) also uses the NLSY79 and investigates how earnings, hours worked, and employment of displaced workers vary by migration status. The sample contains mobile and non-mobile displaced workers, along with a comparison group of individuals who never experience this type of involuntary job loss. The author defines a mobile displaced worker as someone who moved between counties during the first 2 years following job loss and did not return to the original county by the third year following displacement. Using an individual fixed-effects analysis, Gustafson (1998) finds positive, but small, effects for mobile displaced workers. Displaced workers who migrate experience long-term reductions in hours worked and the probability of employment equaling $6 \%$. For their non-mobile counterparts, the decline is $8 \%$. The difference in earnings is somewhat larger. Those displaced workers who move experience long-term earnings losses of $10 \%$, whereas the losses of those who do not migrate equal $15 \%$.

Boman (2011) follows a sample of displaced workers in Sweden after job loss and tracks their earnings around their first post-displacement move. The author defines a mobile displaced worker as someone who moves between local labor markets within the first 2 years following job loss. For the entire sample, Boman (2011) finds negative effects from moving during the first 4 years after migration. During the 7-9 years after the move, the effect on earnings is positive. When delineating the sample by gender, Boman (2011) notes that men experience a consistent positive effect on earnings from migration, whereas women experience a negative effect on earnings. He notes that the reason for migration could cause the gender differences observed in his results since women are traditionally tied-movers.

This paper contributes to the existing literature by focusing on how the costs of job loss vary by workers' post-displacement migration status using a panel dataset of individuals between 25 and 62 years old in the United States. The previous literature has used either cross-sectional data from the DWS (Addison and Portugal 1987; Nord and Ting 1991 and 1992; Herzog and Schlottmann 1995), panel data from the NLSY79, which focuses on younger workers (Gustafson 1998; Yankow 2004), or panel data 
from Sweden (Boman 2011). Results from the analysis will provide information on, and describe, the inter-temporal, long-term relationship between geographic mobility and various labor market outcomes associated with displacement for a group of workers belonging to a broader age range in the United States.

Additionally, this paper contributes to the earlier literature by extending the analysis to examine how migration relates to the probability of homeownership. The earlier literature on displacement and migration has only examined earnings, hours worked, or employment. Since migration requires purchasing a new home or renting a new apartment, the analysis examines how moving alters displaced workers' probability of homeownership. In his analysis of changes in food consumption for displaced and disabled individuals, Stephens (2001) notes how changes in consumption are important for understanding how earnings shocks alter economic well-being. Results from the analysis will add to the understanding of how displacement alters economic well-being when using the probability of homeownership as an alternative form of consumption.

\section{Data and Empirical Methodology}

\subsection{Data}

The data used here come from the Panel Study of Income Dynamics (PSID), which began in 1968. The PSID surveyed households and split-offs from them (e.g., children who grew up and formed their own families) annually until 1997, after which the survey moved to a biennial format. The PSID added a Latino sample in 1990 and 1992 and an immigrant sample in 1997 and 1999. Due to its longitudinal nature, the PSID has been used frequently by researchers for studying the longterm effects job displacement has on various labor market outcomes (e.g., Ruhm 1991; Stevens 1997; Stephens 2001, 2002; Lindo 2010; Jolly 2013). Aside from demographic and economic information, the PSID also contains some data on location of residence and geographic migration. This allows researchers the ability to analyze the inter-temporal relationship between migration and labor market outcomes (e.g., Rogers and Rogers 2000; Cooke et al. 2009).

The data used in the analysis presented here come from the 1968 to 1997 surveys. This study excludes data past 1997 because of the change from an annual survey to a biennial survey starting that year. Therefore, displacements that occur in the off years of the survey $(1998,2000,2002$, etc.) may be missed. Since the purpose of this paper is to analyze the outcomes of displaced workers around the date of job loss and around the first post-separation move, it is important to be able to identify 
the timing of these displacements. Additionally, the Latino and immigrant samples are excluded since they only have data available for a few years.

It is common in the displacement literature to focus on individuals who are at least marginally attached to the labor force. To this end, the unit of analysis is male household heads between the ages of 25 and $62 .^{7}$ To be included in the sample, individuals must reside inside the United States and report non-missing information on earnings, hours worked, and the independent variables used in the estimated equations for at least 2 years. Finally, the analysis excludes any respondent reporting zero labor earnings and zero hours worked for every year he is a household head.

Displacement is identified from a question asked of all individuals who are not working or who have been with their current employer/job for less than 12 months or since January of the previous year. The question asks why the respondent is no longer with his previous employer/job. If he states that the reason is plant closure or lay-off/fire, then he is identified as experiencing a displacement in the calendar year preceding the survey. This is consistent with previous research on displacement using the PSID (e.g., Stephens 2002; Lindo 2010; Jolly 2013).

The analysis follows the first reported displacement since the probability of job loss rises after the initial one (Stevens 1997). Therefore, displacements that occur after the first report may not be exogenous. The 1968 survey asks about displacements that occurred during the previous 10 years. Since job losses reported during the 1968 survey cannot be timed, anyone reporting his first displacement during that survey is removed from the analysis. This restriction reduces the final analysis sample by $4.4 \%$ (280 workers). Of these 280 individuals, 171 never report a subsequent job loss. If included in the sample, then they would be considered non-displaced due to the inability to time the first reported job loss. This would cause the estimated costs of displacement to be closer to zero. The remaining 109 individuals reported subsequent job losses. Stevens (1997) shows that individuals who experience multiple displacements fare worse when compared to those who do not. Therefore, including these workers in the sample would cause the estimated costs of displacement to be worse. When analyzing how migration potentially affects the costs of displacement, this restriction would only bias the estimates if these individuals had unobservable

7 As in Jolly (2013), the analysis excludes females to avoid any potential labor market adjustments caused by divorce, child rearing, etc. Furthermore, the PSID automatically designates the male as the household head in the majority of cases. Therefore, men would constitute a large majority of the sample. Specifically, if females were included in the analysis, then they would constitute less than $29 \%$ of the entire sample. The sample excludes individuals under the age of 25 to avoid schooling decisions and over the age of 62 to avoid retirement decisions. 
characteristics that yield higher or lower propensities to migrate. There is no a priori reason to expect this. Furthermore, only 41 of these workers $(2.6 \%$ of the displaced sample) would be classified as a mobile displaced worker (discussed below). Therefore, any bias caused by this restriction should be minimal.

The purpose of this paper is to analyze how the costs of job loss vary by the migration status of displaced workers and how earnings, hours worked, and time unemployed change around the date of the first post-separation move. Therefore, it is important that displaced workers have information available after the job loss occurs, and this information should contain measures of location. The location measures used in this study include region of residence and an indicator for whether or not an individual is living in an Standard Metropolitan Statistical Area (SMSA). To this end, any displaced worker who does not have information on these location measures during the year of job loss or the first 4 years afterward is removed from the analysis. This requires all men who report their first displacement after 1992 to be removed from the sample. This restriction reduces the final sample of displaced workers by 717 (31.5\%). To see if this alters the results, the main analysis was repeated after removing this restriction. The qualitative results are the same and the quantitative results are little changed and available upon request.

Geographic mobility is determined from a question asking respondents if they moved since spring of the previous year. If the individual responds affirmatively, then he is identified as moving during the calendar year preceding the survey. ${ }^{8}$ Following Gustafson (1998) and Boman (2011), a displaced worker is considered mobile if he moves during the year of job loss, 1 year after, or 2 years after. This 3-year window is used to increase the likelihood that the migration is closely associated with the initial displacement and to make certain that mobile displaced workers have the ability to contribute multiple observations after the move occurs. ${ }^{9,10}$

8 The PSID does contain information on the actual date of moving. However, this is only available for selected years. Specifically, the information on the month of the move is not available between 1968 and 1974 or in 1982. Data on the year of the move is not available until 1993. The PSID conducts almost all of its surveys between March and May (Stephens 2002). Therefore, the probability that the move occurred during the year before the survey is high. Given that the information on the actual date of moving is incomplete and that almost all surveys are conducted early in the year, this paper times the move as occurring during the year before the survey.

9 There is a potential timing issue with the above definition of mobile displaced workers. Since the PSID does not contain information on the exact date of job loss, it is not clear if the move or if the displacement happened first when focusing on the year of separation.

10 This definition of mobility is generous and inclusive. Without further restrictions, this definition risks classifying housing adjustments and pre-job loss migration as job-related moves, which would tend to underestimate migration's effect on reducing the costs of job 
This definition of migration accounts for all cross-state and cross-county moves in addition to all moves that occur within a state and within a county. As Boman (2011) notes, longer-distance moves are generally regarded as labor market oriented. The available information in the PSID on a person's location of residence is limited. Information on the distance of migration is not available. This lack of information does not allow for a deeper understanding as to whether displaced workers may be moving to more economically favorable areas. In addition, it does not allow for an investigation into whether longer distance moves are more or less beneficial than shorter distance moves, which limits the scope of the analysis.

To distinguish long-distance from short-distance moves, the migration literature typically uses boundary-based definitions. Long-distance moves are then defined as those that cross-geographic boundaries. It is possible to identify crossstate moves in the PSID. Unfortunately, the sample of mobile displaced workers who move between states is relatively small (equaling 113), which limits the scope of the analysis. ${ }^{11}$ However, as Boman (2011) notes, some moves that occur within geographic boundaries require a longer distance than those that cross these borders. Therefore, there is no guarantee that cross-state or cross-county moves require a long distance; and, there is no guarantee that these cross-border moves are labor market oriented. However, it is still important to account for moves that occur for job-related versus other reasons. The PSID does ask respondents the reason for the move. To account for mobility that is associated more closely with the labor market, the empirical methodology discussed below is repeated using all non-mobile displaced workers and those who migrate within the first 2 years after job loss and state that their main reason for moving is, what the PSID terms, "purposive productive," which includes reasons such as taking a new job. ${ }^{12}$

\subsection{Empirical Methodology}

The first step in the analysis is to estimate the costs of job loss and analyze how these costs vary depending upon the migration status of displaced workers. To

\footnotetext{
loss. Several robustness checks in Section 4 discuss this issue further. However, the main results presented below should be interpreted with this in mind.

11 An individual's county of residence is not available. Therefore, it is not possible to identify cross-county moves.

12 The purposive productive categorical response includes reasons other than taking a new job, such as transfers, ending school and to get nearer to work. However, the purposive productive category most closely matches the migration variables used in the early literature on displacement and migration (Addison and Portugal 1987; Nord and Ting 1991; 1992; Herzog and Schlottmann 1995).
} 
this end, the general form of the estimated equation, which is the same as that used by Gustafson (1998), is

$$
y_{i t}=x_{i t}^{\prime} \beta+\sum_{k \geq-2} D_{i s}^{k} \delta_{k}+\sum_{k \geq-2} M_{i s}^{k} \varphi_{k}+\gamma_{t}+\alpha_{i}+\varepsilon_{i t}
$$

Here, $y_{i t}$ equals either the log of annual labor earnings, annual hours worked, or the amount of hours unemployed for individual $i$ in year $t$. Earnings are converted to real 1996 dollars by using the consumer price index for all urban consumers. ${ }^{13}$ Data on hours unemployed is not available past 1992. Those particular years are excluded from the estimation when hours unemployed is the dependent variable. The $x_{i t}$ includes a quadratic in potential experience, which equals age minus education minus 6 . If the individual has fewer than 12 years of education, then experience equals age minus 18 so that he is not overcompensated and assigned larger values of experience (Stephens 2002). Education is constant and equals the years of completed education reported in the last year the individual is in the survey. Additional variables included in $x_{i t}$ are the number of children in the family unit under 18 years old and indicator variables for marital status, having a working spouse, homeownership, holding a blue-collar occupation, region of residence, and living in an SMSA. ${ }^{14}$ The $\gamma_{t}$ 's are a set of year dummy variables, which control for year-specific macroeconomic conditions (i.e., business cycles).

The $D_{i s}{ }^{k}$ is a set of dummy variables equaling 1 if individual $i$ experiences a displacement in year $s$, and $k$ indexes these variables starting 2 years before job loss. The variable $M_{i s}{ }^{k}$ is an interaction between $D_{i s}{ }^{k}$ and an indicator equaling 1 if the individual is a mobile displaced worker. This specification allows the costs of job loss to vary by mobility status. Estimates of $\delta_{k}$ show the costs for nonmobile displaced workers; estimates of $\delta_{k}+\varphi_{k}$ are the costs for those workers who migrate within 2 years after separation occurs. These estimates indicate displacement's effect on log earnings, hours worked, and hours unemployed in relation to workers who never experience this type of involuntary job loss.

The term $\alpha_{i}$ is treated as a fixed effect and accounts for any time-invariant, individual-specific, unobserved heterogeneity that may be correlated with the observed regressors. Some research suggests that displaced individuals are

13 Nominal figures are converted to 1996 dollars because the earnings variable in the PSID refers to earnings in the previous calendar year. Therefore, the last calendar year for which earnings information used in this study is 1996.

14 Additional variables used in regressions not reported include a measure of the county unemployment rate and an indicator for working in the manufacturing industry. The results are little changed and available upon request. These variables are not included in the main results presented below because of limited data availability. The county unemployment rate is not available in 1969, 1974, and past 1992. Data on industry of occupation is not available until 1971. 
different from other workers and that there is a potential correlation between $D_{i s}{ }^{k}$ and other unobservable attributes (Gibbons and Katz 1991; Couch and Placzek 2010). Additionally, those individuals who migrate may be self-selected, either positively or negatively (Gustafson 1998; Yankow 2004; Boman 2011). Therefore, it is important to try to account for any unobserved heterogeneity that is correlated potentially with the $D_{i s}{ }^{k}$ or $M_{i s}{ }^{k}$. Finally, $\varepsilon_{i t}$ is a time-varying error term. The sample of workers included in the estimation of eq. [1] is all nondisplaced individuals, all non-mobile displaced workers, and those who are displaced and move within the first 2 years following job loss. Estimates are also presented when including all non-displaced and non-mobile displaced workers, and mobile displaced workers who move for purposive productive (i.e., job-related) reasons.

Equation [1] provides estimates of the costs associated with displacement around the year of job loss. The second step in the methodology is to analyze and describe the inter-temporal relationship between migration and displaced workers' earnings, hours worked, and time unemployed. Following Boman (2011), the analysis sample is restricted to displaced workers only and uses their observations during and after the year of job loss. Post-displacement outcomes are then tracked around the date of the first move made between the year of separation and 2 years afterward. Equation [1] becomes

$$
y_{i t}=x_{i t}^{\prime} \omega+\sum_{k \geq 0} m_{i s}^{k} \vartheta_{k}+\gamma_{t}+\alpha_{i}+\varepsilon_{i t}
$$

Here, $m_{i s}{ }^{k}$ is a set of dummy variables equaling 1 if displaced worker $i$ moves in year $s$, and $k$ indexes these variables starting with the year of the move. Estimates of $\vartheta_{k}$ show the inter-temporal relationship between the first postdisplacement migration and earnings, hours worked, and hours unemployed. Other variables are defined as before. To compare homeownership patterns of mobile and non-mobile displaced workers, eq. [2] is estimated an additional time, where $y_{i t}$ equals 1 if the individual is a homeowner in period $t$ and 0 otherwise.

It is possible that attrition will bias results from eqs [1] and [2] toward finding positive effects from migration. Attrition from the PSID is concentrated among those individuals with unstable earnings and migration histories and who have lower socioeconomic status (Fitzgerald, Gottschalk, and Moffitt 1998). Therefore, displaced workers who remain in the analysis sample used here may have relatively higher earnings, and more stability in earnings, when compared to those who attrite. Additionally, those displaced workers who migrate and remain in the sample may have better post-migration outcomes when compared to those who attrite. The analysis presented here does not address the issue of attrition. 


\subsection{Selection into Migration}

The analysis accounts for self-selection into migration in eqs [1] and [2] by including individual fixed-effects, $\alpha_{i}$. Doing so accounts for any unobservable, individual-specific heterogeneity that is time invariant. While other methods are available to account for selection, such as instrumental variables (IV), the use of individual fixed effects is common in the migration literature. Researchers have used models similar in style to eq. [2] to study migration's effect on income (Pekkala 2002), male earnings (Rodgers and Rodgers 2000), and on the earnings of women and the gender pay gap (Cooke et al. 2009). In fact, Boman (2011) argues against the use of IV methods since the migration decision depends upon unobservable factors, leading to weak instruments for mobility. ${ }^{15}$

It is possible that there are unobservable differences between workers that vary over time. Accounting for this is important potentially since individuals make migration decisions based upon the stream/trend of earnings. Therefore, workers may have individual-specific, unobservable trends that are related to earnings and the decision to migrate. To account for unobservable heterogeneity that contains a trend and level effect, eq. [1] is redefined as

$$
y_{i t}=x_{i t}^{\prime} \beta+\sum_{k \geq-2} D_{i s}^{k} \delta_{k}+\sum_{k \geq-2} M_{i s}^{k} \varphi_{k}+\gamma_{t}+\alpha_{i}+\lambda_{i} t+\varepsilon_{i t}
$$

The addition of $\lambda_{i} t$ accounts for any individual-specific, unobservable linear trends that could be correlated with the dependent and independent variables. Similarly, eq. [2] becomes

$$
y_{i t}=x_{i t}^{\prime} \omega+\sum_{k \geq 0} m_{i s}^{k} \vartheta_{k}+\gamma_{t}+\alpha_{i}+\lambda_{i} t+\varepsilon_{i t}
$$

15 Boman (2011) estimates the same form of eq. [2] as a random-effects Tobit model. A random-effects model is not used in this analysis. For random-effects models to produce unbiased and consistent estimates there must be no correlation between the independent variables and the unobserved effect, $\alpha_{i}$, which is a relatively strong assumption. If $\alpha_{i}$ contains innate ability, for example, and those who migrate self-select based on ability, then a non-zero correlation would exist between the migration variables and $\alpha_{i}$. To proxy for ability, Boman (2011) includes earnings from the year preceding displacement as an additional explanatory variable in the estimated equations. This earnings variable is time invariant for each worker in the panel, which inherently assumes that ability is also time invariant. Since this is the case, it is just as reasonable to assume that there is a non-zero correlation between the independent variables and $\alpha_{i}$, and treat $\alpha_{i}$ as a fixed effect. Furthermore, the broader job displacement literature assumes that this non-zero correlation exists and estimates linear fixed-effects models (Jacobson, LaLonde, and Sullivan 1993; Stevens 1997; Stephens 2001, 2002; Couch and Placzek 2010; Lindo 2010; Jolly 2013). Therefore, to maintain consistency with the broader job displacement literature, fixed-effects models are used in this analysis. 
The entire analysis was replicated using eqs [1'] and [2'], and results are in Appendix Tables 6 and 7, respectively. In general, the main qualitative findings still hold.

An additional strategy to account for the potential effect of unobservable differences between workers is to focus on a more exogenous source of variation. The analysis here identifies a worker as displaced if he experiences a job loss due to a plant closure or being laid-off/fired, which is standard in the literature on displacement using the PSID. The literature generally agrees that displacements caused by plant closures are more exogenous than those caused by individual layoffs/firings. Equations [1] and [2] were re-estimated after removing from the sample all displaced workers who experience a job loss due to being laid-off/fired. The results are in appendix Tables 8 and 9, respectively. The qualitative findings still hold. ${ }^{16}$

Finally, Gabriel and Schmitz (1995) and Rodgers and Rodgers (2000) suggest a test for self-selection into migration. The following equation is estimated on a sample of displaced workers using observations only during the third year before job loss occurs:

$$
y_{i}=x_{i}^{\prime} \beta+\theta M_{i}+\gamma_{t}+\varepsilon_{i}
$$

Here, $y_{i}$ equals either the log of annual labor earnings, hours worked, or time unemployed. The $x_{i}$ and $\gamma_{t}$ are defined as before. The variable $M_{i}$ is an indicator equaling 1 if the displaced worker eventually moves between the year of job loss and 2 years afterward. If the parameter estimate associated with $M_{i}$ is statistically significant, then self-selection may be present since this would suggest that future movers have significantly different labor market outcomes than nonmigrants after conditioning on observable characteristics contained in $x_{i}$. The parameter estimate associated with $M_{i}$ was statistically insignificant in each regression. Results are in appendix Table 10.

\section{Results}

Table 1 presents descriptive statistics for mobile and non-mobile displaced workers and the comparison group of individuals who never experience this type of involuntary job loss. The first column displays the variables of interest. Column 2

16 When interpreting the results from Tables 8 and 9, it should be kept in mind that when delineating by type of displacement, mobility status, and reason for migrating, sample sizes become small. There are 527 workers displaced by plant closure. Of those, 235 move between the year of job loss and 2 years afterward and 42 move for job-related reasons. 
Table 1: Descriptive statistics of selected variables.

\begin{tabular}{lccc}
\hline Variable & Non-displaced & & Displaced \\
\cline { 3 - 4 } & & Non-mobile & Mobile \\
\hline Labor earnings $^{\mathrm{a}}$ & $\$ 40,384.72$ & $\$ 35,547.38$ & $\$ 31,464.13$ \\
Annual hours worked $^{\text {Hours unemployed }}{ }^{\mathrm{b}}$ & $2,125.29$ & $2,113.57$ & $2,080.91$ \\
Age & 27.52 & 76.00 & 125.25 \\
Education & 40.15 & 37.85 & 32.74 \\
Married & 12.82 & 12.03 & 12.68 \\
\# children $<18$ & $87.85 \%$ & $89.59 \%$ & $74.41 \%$ \\
Homeowner & 1.32 & 1.63 & 1.27 \\
Spouse annual hours worked & & $70.00 \%$ & $38.64 \%$ \\
Blue collar occupation & $101.76 \%$ & 999.35 & 914.06 \\
Living in SMSA $^{c}$ & $39.30 \%$ & $58.35 \%$ & $47.83 \%$ \\
Region of residence & $59.22 \%$ & $63.22 \%$ & $69.27 \%$ \\
Northeast & & & \\
North Central & $15.87 \%$ & $20.41 \%$ & $14.33 \%$ \\
South & $26.06 \%$ & $22.07 \%$ & $23.81 \%$ \\
West $^{\text {d }}$ & $42.54 \%$ & $42.81 \%$ & $43.77 \%$ \\
Sample size & $15.54 \%$ & $14.72 \%$ & $18.09 \%$ \\
\hline
\end{tabular}

Source: Author's calculations using the 1968-1997 waves of the PSID. For non-displaced workers, calculations use all person-year observations. For displaced workers, calculations use the observations for the 2 years prior to job loss.

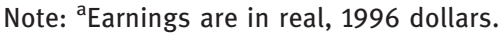

${ }^{b}$ Data not available past 1992. Those years are ignored in the calculation.

'Only calculated using observations for married individuals.

Includes Alaska and Hawaii.

shows the statistics for the comparison group, column 3 is for non-mobile displaced workers, and the final column presents the numbers for those who experience a job loss and move within the first 2 years after separation. For nondisplaced workers, the statistics are calculated using all person-year observations. For the displaced samples, the calculations use the 2 years before job loss.

There are 6,074 total workers in the sample. Of those, 1,554 experience a displacement, 772 move within the first 2 years after job loss, and 135 migrate for job-related reasons. When comparing mobile and non-mobile displaced workers, Table 1 indicates that those who move tend to exhibit the typical characteristics of migrants. They are younger, less likely to be married or a homeowner, and have fewer children under 18 . The wives of mobile displaced workers tend to have lower annual hours worked when compared to their non-mobile counterparts, which potentially indicates that these wives are tied movers. Migrants are 
less likely to hold a blue-collar occupation and are more likely to live in an SMSA prior to job loss.

Interestingly, mobile displaced workers seem to have worse labor market performance during the 2 years before separation when compared to the nonmobile. Earnings and annual hours worked are lower and average hourly unemployment is higher for this particular group. This suggests that those workers who move after job loss either are negatively selected, or are trying to escape from poor local labor markets as suggested by Herzog and Schlottmann (1995) and shown by Yankow (2004). Given that mobile displaced workers have higher education, on average, when compared to the non-mobile group, the latter appears to be more likely. Finally, non-displaced workers have higher labor earnings, spend less time unemployed, are older, work more hours per year, and have lower probabilities of holding a blue-collar occupation and living in an SMSA when compared to both groups experiencing a job loss.

\subsection{Costs of Job Loss}

Table 2 presents estimates of the costs of job loss by post-displacement mobility status from eq. [1]. The dependent variables used in the regressions are the log of annual labor earnings, annual hours worked, and annual hours spent unemployed. The rows labeled "2 years before" through "10 years after" represent time relative to displacement. Columns labeled "Non-mobile" present estimates of $\delta_{k}$, and the columns labeled "Mobile" show the estimates of $\delta_{k}+\varphi_{k}$ when using the sample of all displaced workers and the comparison group. Finally, columns labeled "Job mobile" show estimates of $\delta_{k}+\varphi_{k}$ when using the sample of non-mobile displaced workers, the comparison group, and those mobile displaced workers who move for job-related reasons. Estimates of $\delta_{k}$ are not shown from this sample because they are similar in magnitude when compared to those in the "Non-mobile" columns.

Table 2 indicates that non-mobile displaced workers experience large and persistent earnings losses. During the year after separation, non-mobile workers experience a decline in earnings equaling $24 \%$ when compared to non-displaced individuals. $^{17}$ These losses persist, equaling 10\% even 10 years after separation occurs. Mobile displaced workers fare better than their non-mobile counterparts do; every post-displacement estimate is smaller in absolute value. Estimates are generally insignificant starting 5 years after displacement, indicating that earnings losses do not persist for this group. Furthermore, estimates for the mobile

17 The percentage change in earnings is calculated from $e^{\beta}-1$. 


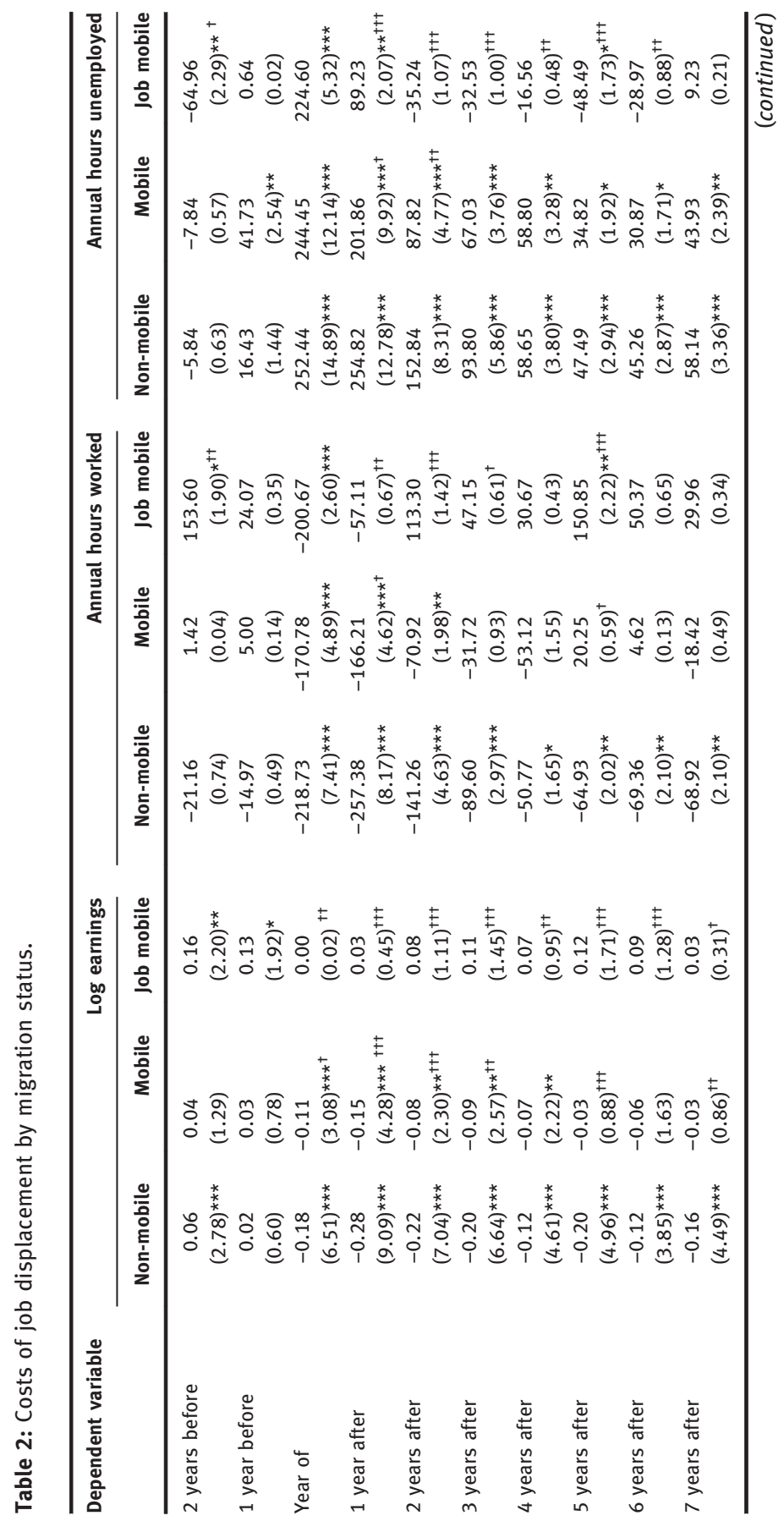




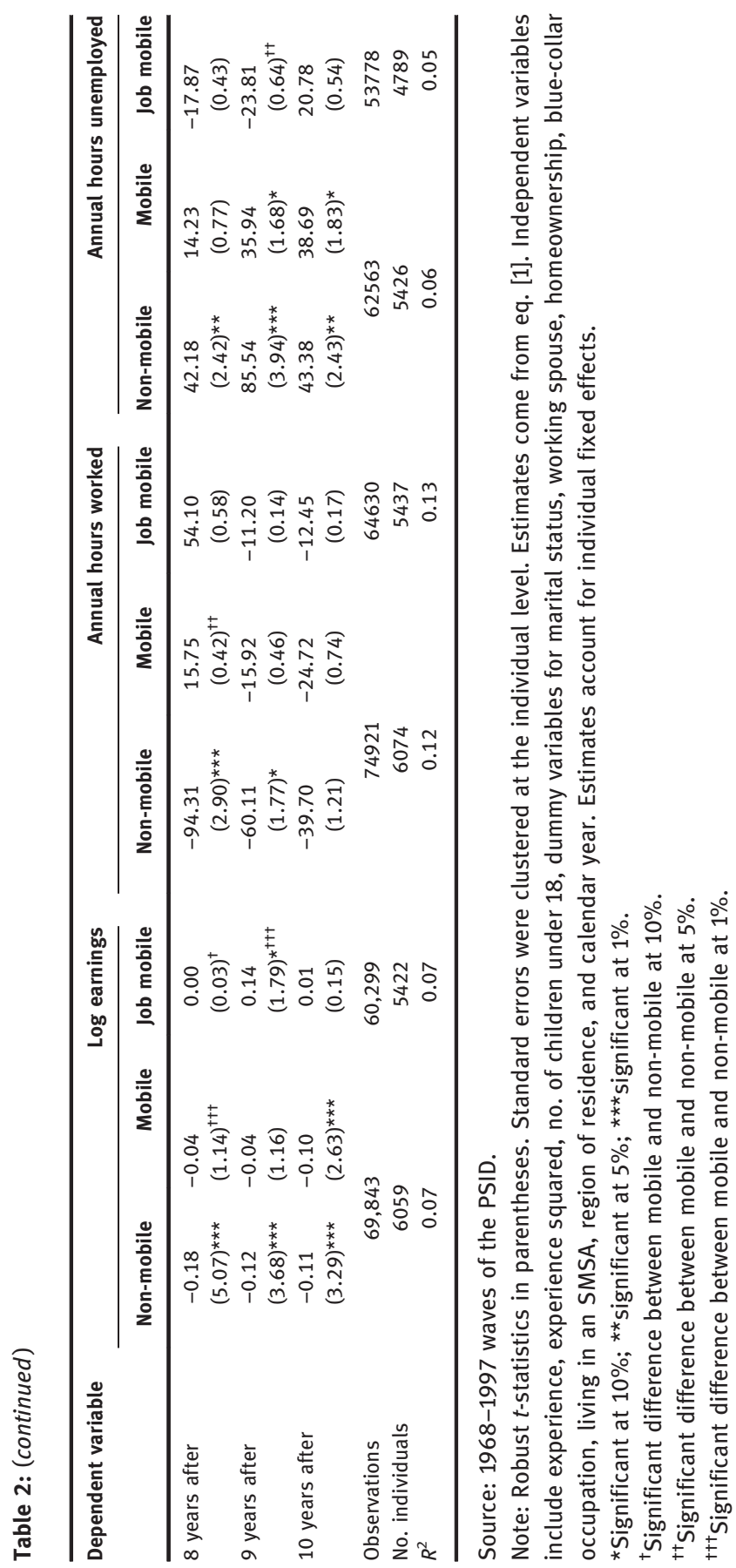


group are statistically different from those of the non-mobile during the year of job loss and for six of the post-displacement years. These qualitative results are more pronounced for those workers who migrate for job-related reasons. Almost none of the post-displacement variables is statistically significant, and each estimate in column 4 is smaller in absolute value when compared to any estimate in columns 2 or 3. Additionally, the estimates for the year of displacement through 9 years afterward are statistically different from the non-mobile displaced group.

The results for hours worked are qualitatively similar to those for earnings. During the year of job loss, non-mobile displaced workers experience a drop in hours worked in relation to the comparison group of non-displaced individuals amounting to $219 \mathrm{~h}$. The year after displacement, losses equal $257 \mathrm{~h}$. Assuming a 40-h-work week, this translates into approximately five and six weeks of lost work, respectively. While the post-displacement variables are statistically significant until the ninth year after separation, the estimates are economically small starting in the fifth year after job loss. For example, in the fifth year after displacement, lost hours worked equal 65, which is approximately only 1.5 weeks.

For mobile displaced workers, the estimated reduction in hours worked is smaller in absolute value for nearly every post-displacement year. ${ }^{18}$ Additionally, the results show that estimates are statistically insignificant for the mobile group starting in the third year after job loss; three of the postdisplacement variables are statistically different from the non-mobile displaced group. Those who move for job-related reasons fare even better. This group experiences a statistically significant drop in hours worked during the year of job loss equaling 200. However, starting with the first year after displacement, those who move for job-related reasons do not experience any statistically significant drop in hours worked for the remainder of the follow-up period. The estimates for those who move for purposive productive reasons are statistically different from the non-mobile group during four of the post-displacement years.

Table 2 shows that workers experience an increase in hours unemployed during the year of displacement regardless of mobility status. Increases in hours unemployed equal 252 for the non-mobile group, 244 for all mobile displaced workers, and 225 for those who move for job-related reasons. Nearly all

18 The only exception is the fourth year after displacement. Here, non-mobile displaced workers experience a reduction in hours equaling 50, whereas the mobile group has a reduction equaling $53 \mathrm{~h}$. However, the estimate for the mobile group is statistically insignificant. 
post-displacement estimates are smaller for those who move, particularly when moving for job-related reasons. In fact, job-related movers experience no significant increase in unemployment after the first year following separation. Increases in unemployment are economically small starting in the fourth and fifth years after displacement for mobile and non-mobile workers. This is consistent with previous research on displaced workers and unemployment and indicates that even though there is a lasting effect on earnings, the effect on unemployment does not persist (Ruhm 1991).

When applying the same methodology to the NLSY79, Gustafson (1998) finds that, during the first 24 quarters after separation, earnings losses for mobile displaced men are 14- to 18-percentage points smaller than the losses for non-mobile men are. ${ }^{19}$ When comparing mobile and non-mobile displaced men in this analysis, the differential is never more than 15-percentage points. ${ }^{20}$ Since the NLSY79 focuses on younger individuals, it appears that, on average, younger displaced workers benefit relatively more from migration when compared to workers in the broader age range used in this analysis.

\subsection{Migration and Post-displacement Outcomes}

To examine the relationship between mobility and various post-separation outcomes, this section focuses on displaced workers only, follows them starting with the year of job loss, and tracks log earnings, hours worked, and time unemployed around the date of the first post-displacement move that occurs within the first 2 years after separation. Table 3 presents the results from eq. [2]. Rows labeled "Year of" through "10 years after" now represent time relative to migration. Entries in the "Mobile" column are the estimates of $\vartheta_{k}$ when the sample includes all displaced workers. Numbers in the "Job Mobile" column are estimates of $\vartheta_{k}$ when the sample is all non-mobile displaced workers and those who move for job-related reasons.

The results in Table 3 indicate that mobile displaced workers' earnings tend to increase after migration. However, this increase does not occur

19 When focusing solely on male workers, Gustafson (1998) only estimates earnings losses and employment probabilities.

20 When comparing non-mobile displaced workers and those who move for job-related reasons, the earnings loss differential ranges from 12- to 30-percentage points. Gustafson (1998) does not present separate estimates by reason for migration. Therefore, direct comparisons to these results are not possible. 
Table 3: Migration's potential impact on post-displacement outcomes.

\begin{tabular}{|c|c|c|c|c|c|c|}
\hline \multirow[t]{2}{*}{ Dependent variable } & \multicolumn{2}{|c|}{ Log earnings } & \multicolumn{2}{|c|}{ Hours worked } & \multicolumn{2}{|c|}{ Hours unemployed } \\
\hline & Mobile & Job mobile & Mobile & Job mobile & Mobile & Job mobile \\
\hline Year of & $\begin{array}{r}0.06 \\
(1.54)\end{array}$ & $\begin{array}{c}0.16 \\
(1.77)^{\star}\end{array}$ & $\begin{array}{l}74.19 \\
(1.85)^{\star}\end{array}$ & $\begin{array}{r}126.72 \\
(1.42)\end{array}$ & $\begin{array}{r}-30.66 \\
(1.28)\end{array}$ & $\begin{array}{r}-20.62 \\
(0.39)\end{array}$ \\
\hline 1 year after & $\begin{array}{r}0.04 \\
(0.95)\end{array}$ & $\begin{array}{c}0.24 \\
(2.52)^{\star \star}\end{array}$ & $\begin{array}{l}99.36 \\
(2.50)^{\star \star}\end{array}$ & $\begin{array}{l}409.30 \\
(4.33)^{\star \star \star}\end{array}$ & $\begin{array}{l}-73.11 \\
(3.17)^{\star \star \star}\end{array}$ & $\begin{array}{l}-232.72 \\
(4.97)^{\star \star \star}\end{array}$ \\
\hline 2 years after & $\begin{array}{c}0.06 \\
(1.65)^{\star}\end{array}$ & $\begin{array}{c}0.27 \\
(3.51)^{\star \star \star}\end{array}$ & $\begin{array}{l}124.79 \\
(3.22)^{\star \star \star}\end{array}$ & $\begin{array}{l}371.00 \\
(4.41)^{\star \star \star}\end{array}$ & $\begin{array}{l}-127.11 \\
(5.69)^{\star \star \star}\end{array}$ & $\begin{array}{l}-267.60 \\
(6.13)^{\star \star \star}\end{array}$ \\
\hline 3 years after & $\begin{array}{c}0.07 \\
(1.81)^{\star}\end{array}$ & $\begin{array}{c}0.25 \\
(2.84)^{\star \star \star \star}\end{array}$ & $\begin{array}{l}156.07 \\
(4.10)^{\star \star \star}\end{array}$ & $\begin{array}{l}260.60 \\
(3.08)^{\star \star \star \star}\end{array}$ & $\begin{array}{r}-122.59 \\
(5.49)^{\star \star \star}\end{array}$ & $\begin{array}{r}-206.64 \\
(4.62)^{\star \star \star}\end{array}$ \\
\hline 4 years after & $\begin{array}{c}0.08 \\
(2.17)^{\star \star}\end{array}$ & $\begin{array}{c}0.25 \\
(2.94)^{\star \star \star}\end{array}$ & $\begin{array}{l}140.92 \\
(3.75)^{\star \star \star}\end{array}$ & $\begin{array}{l}309.07 \\
(3.93)^{\star \star \star \star}\end{array}$ & $\begin{array}{l}-118.76 \\
(5.43)^{\star \star \star}\end{array}$ & $\begin{array}{l}-225.24 \\
(5.34)^{\star \star \star}\end{array}$ \\
\hline 5 years after & $\begin{array}{c}0.08 \\
(2.36)^{\star \star}\end{array}$ & $\begin{array}{c}0.27 \\
(3.28)^{\star \star \star}\end{array}$ & $\begin{array}{l}181.15 \\
(4.81)^{\star \star \star}\end{array}$ & $\begin{array}{l}408.94 \\
(4.80)^{\star \star \star}\end{array}$ & $\begin{array}{l}-132.75 \\
(6.22)^{\star \star \star}\end{array}$ & $\begin{array}{l}-192.92 \\
(4.87)^{\star \star \star}\end{array}$ \\
\hline 6 years after & $\begin{array}{c}0.07 \\
(1.77)^{\star}\end{array}$ & $\begin{array}{c}0.21 \\
(2.47)^{\star \star}\end{array}$ & $\begin{array}{l}158.09 \\
(4.02)^{\star \star \star}\end{array}$ & $\begin{array}{l}290.10 \\
(2.85)^{\star \star \star}\end{array}$ & $\begin{array}{l}-105.21 \\
(4.87)^{\star \star \star}\end{array}$ & $\begin{array}{r}-141.91 \\
(3.08)^{\star \star \star}\end{array}$ \\
\hline 7 years after & $\begin{array}{c}0.07 \\
(1.80)^{\star}\end{array}$ & $\begin{array}{c}0.15 \\
(1.65)^{\star}\end{array}$ & $\begin{array}{l}115.71 \\
(3.04)^{\star \star \star}\end{array}$ & $\begin{array}{c}172.31 \\
(1.82)^{\star}\end{array}$ & $\begin{array}{l}-75.54 \\
(3.59)^{\star \star \star}\end{array}$ & $\begin{array}{l}-130.16 \\
(2.59)^{\star \star \star}\end{array}$ \\
\hline 8 years after & $\begin{array}{r}0.05 \\
(1.22)\end{array}$ & $\begin{array}{r}0.16 \\
(1.64)\end{array}$ & $\begin{array}{l}100.64 \\
(2.60)^{\star \star \star \star}\end{array}$ & $\begin{array}{r}148.56 \\
(1.59)\end{array}$ & $\begin{array}{l}-86.51 \\
(4.09)^{\star \star \star}\end{array}$ & $\begin{array}{r}-162.38 \\
(3.59)^{\star \star \star}\end{array}$ \\
\hline 9 years after & $\begin{array}{r}0.00 \\
(0.06)\end{array}$ & $\begin{array}{r}0.12 \\
(1.21)\end{array}$ & $\begin{array}{l}76.31 \\
(2.13)^{\star \star}\end{array}$ & $\begin{array}{c}155.93 \\
(1.71)^{\star}\end{array}$ & $\begin{array}{l}-52.06 \\
(2.12)^{\star \star}\end{array}$ & $\begin{array}{l}-142.30 \\
(3.30)^{\star \star \star}\end{array}$ \\
\hline 10 years after & $\begin{array}{l}-0.02 \\
(0.40)\end{array}$ & $\begin{array}{c}0.17 \\
(2.19)^{\star \star}\end{array}$ & $\begin{array}{l}51.39 \\
(1.56)\end{array}$ & $\begin{array}{l}87.05 \\
(0.99)\end{array}$ & $\begin{array}{l}-67.51 \\
(3.00)^{\star \star \star}\end{array}$ & $\begin{array}{l}-109.41 \\
(2.59)^{\star \star \star}\end{array}$ \\
\hline Observations & 17,868 & 10,477 & 19,592 & 11,504 & 15,948 & 9,366 \\
\hline No. of individuals & 1554 & 917 & 1554 & 917 & 1554 & 917 \\
\hline$R^{2}$ & 0.05 & 0.05 & 0.08 & 0.09 & 0.07 & 0.07 \\
\hline
\end{tabular}

Source: 1968-1997 waves of the PSID.

Note: Robust $t$-statistics in parentheses. Standard errors were clustered at the individual level. Estimates come from eq. [2]. Independent variables include experience, experience squared, no. of children under 18, dummy variables for marital status, working spouse, homeownership, blue-collar occupation, living in an SMSA, region of residence, and calendar year. Estimates account for individual fixed effects.

*Significant at $10 \%$; ** significant at $5 \%$; ${ }^{* \star *}$ significant at $1 \%$.

until the second year after the move. Estimates are only significant until the seventh year following migration, which indicates that the increase in mobile displaced workers' earnings is not persistent. Statistically significant estimates range from $6 \%$ to $8 \%$. Those moving for job related reasons fare better when compared to moving in general. Specifically, job-related movers experience an increase in earnings, when compared to non-mobile displaced workers, equaling $17 \%$ the year the move occurs. Migration's potential effect on earnings increases to $31 \%$ during the fifth year after moving. Interestingly, the increase in earnings returns to $16 \%$ during the seventh year afterward. 
Unlike earnings, there is a more immediate and lasting increase in hours worked. During the year of the move, mobile displaced workers experience an increase in hours worked equaling 74 when compared to those who do not move within a short time after separation occurs. The effect grows, equaling $181 \mathrm{~h} 5$ years afterward. By the ninth year after migration, mobile displaced workers are still working $76 \mathrm{~h}$ more when compared to their non-mobile counterparts. Again, larger increases in hours worked occur for those moving for job-related reasons. Finally, the results for hours unemployed are qualitatively similar to those for hours worked. There is an almost immediate and lasting decrease in unemployment. Those displaced workers who move experience significantly fewer hours unemployed when compared to non-movers starting the year after migration. Migration has an increasing, and then decreasing effect over time, and those who move for job-related reasons fare better than movers do in general. ${ }^{21}$

There are interesting differences between the results in this section for the United States and those found in Boman (2011) for Sweden. When focusing on males, Boman (2011) finds a consistent, positive, and increasing effect from migration on earnings starting with the third year following the move. Alternatively, this study shows that the increase in earnings is not significant until the second year after the move for mobile displaced workers in general. Furthermore, migration's potential effect on earnings is relatively constant, ranging from $6 \%$ to $8 \%$, and only lasts until the seventh year after the move. ${ }^{22}$

So far, the analysis has focused on the inter-temporal relationship between migration and various post-displacement outcomes, with a specific focus on moves that occur for job-related reasons. However, other reasons for migration exist. These additional reasons may be correlated with a worker's human capital and/or unobservable characteristics. Migration may have different relationships with post-displacement outcomes depending upon these different reasons. The PSID provides three additional categorical responses to the question asking why

21 The PSID does not contain information on the exact date of job loss. Therefore, it is not clear if the move or if the displacement happened first when focusing on the year of separation. This may tend to understate the potential benefits of geographic mobility. The analysis in Table 3 was repeated after removing all individuals who experience their first post-displacement move during the year of job loss. The results from these sensitivity checks are more pronounced and available upon request. The sample of mobile displaced workers used here allows displacement and migration to occur in the same year to help increase sample size and maintain consistency with the earlier literature (Gustafson 1998; Boman 2011).

22 Numerical comparisons cannot be made since Boman (2011) measures earnings in Swedish krona as opposed to the natural log. Additionally, Boman (2011) does not provide separate estimates based upon the reason for migration. Therefore, no comparisons are made for those moving for job-related reasons. 
an individual migrated - consumption, involuntary, and ambiguous. Examples of consumption moves include wanting more/less space, a better house, less rent, to own home, a better neighborhood, or getting married. ${ }^{23}$ Reasons for an involuntary move are dwelling unit coming down, eviction, entering the armed services, health reasons, divorce, or retiring because of health. Ambiguous reasons include saving money, old neighbors moved away, or retiring.

Equation [2] was re-estimated on various subsamples of displaced workers to investigate the relationships between migration and post-displacement outcomes based on different reasons for moving. The results are in Table 4. The column headings represent the subsample used in the analysis. For example, the column labeled "Consumption" presents results when the sample includes all non-mobile displaced workers and those who move for consumption reasons. Concentrating on log earnings, nearly all post-migration variables are insignificant when the move is for consumption, involuntary, or ambiguous reasons. Results are slightly different for hours worked. Almost all of the post-migration variables are statistically insignificant when moving for involuntary or ambiguous reasons. There is a statistically significant, positive impact when moving for consumption reasons. However, the estimates are not as large, immediate, or long-lasting when compared to moving for job-related reasons. Finally, migration is associated with a reduction in time unemployed for all reasons except for ambiguous. However, the results are not as long-lasting or as large, in absolute value, when compared to those when moving for job-related reasons. In general, these results indicate that migration tends to be beneficial for displaced workers when it occurs mainly for job-related reasons. ${ }^{24}$

\subsection{Migration and Homeownership}

Stephens (2001) examines food consumption patterns for displaced and disabled individuals around the date of job loss and disability onset, respectively. Because of the permanent income hypothesis, he notes how changes in

23 Starting in 1975, the PSID delineated the consumption response into four separate categories.

24 In addition to the analyses discussed so far, three separate robustness checks were performed after loosening some of the sample selection criteria. First, female household heads were included in the sample. Second, the age restriction was removed. Finally, the requirement that all displaced workers have location information available during the first 4 years following job loss was removed. Equation [2] was then re-estimated three times, once each for the three different criteria. In each case, the main qualitative findings held and the quantitative findings were little changed. These results are available upon request. 


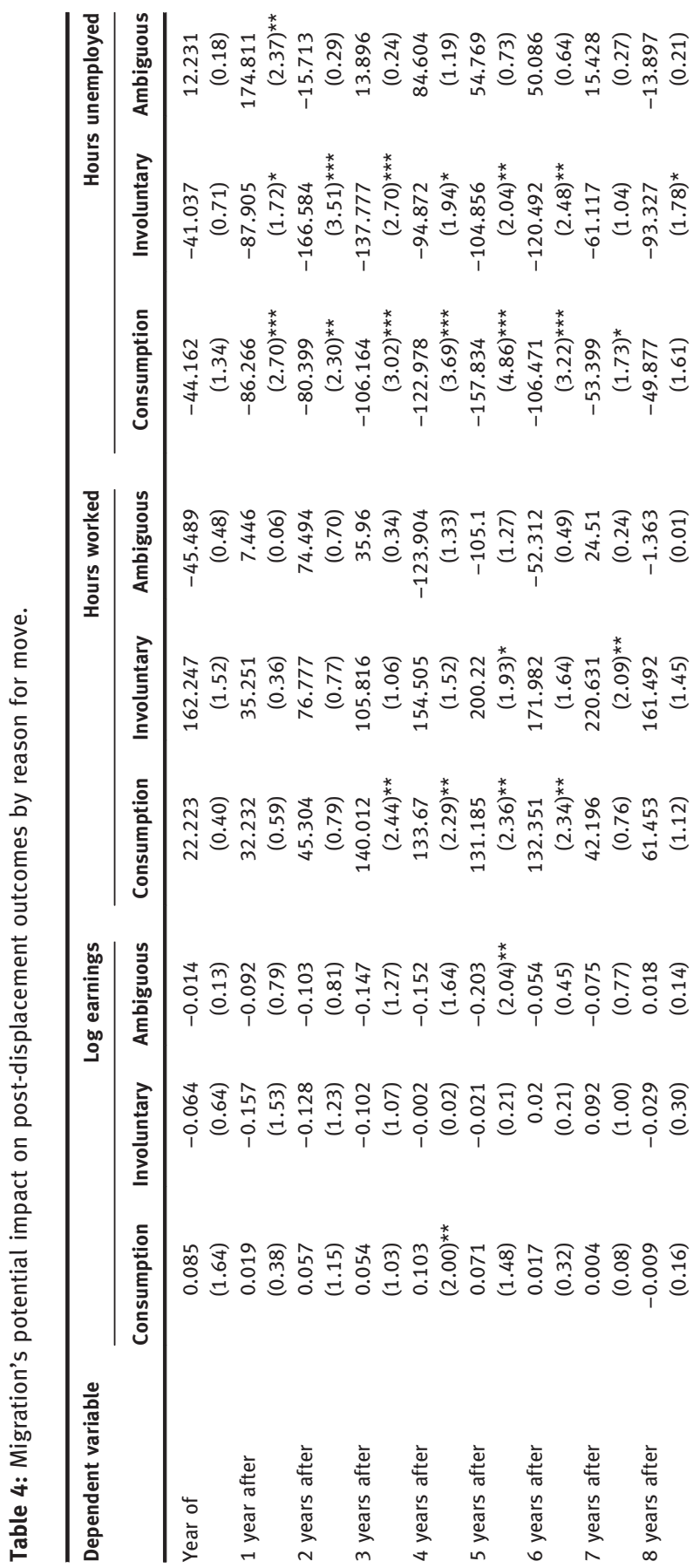




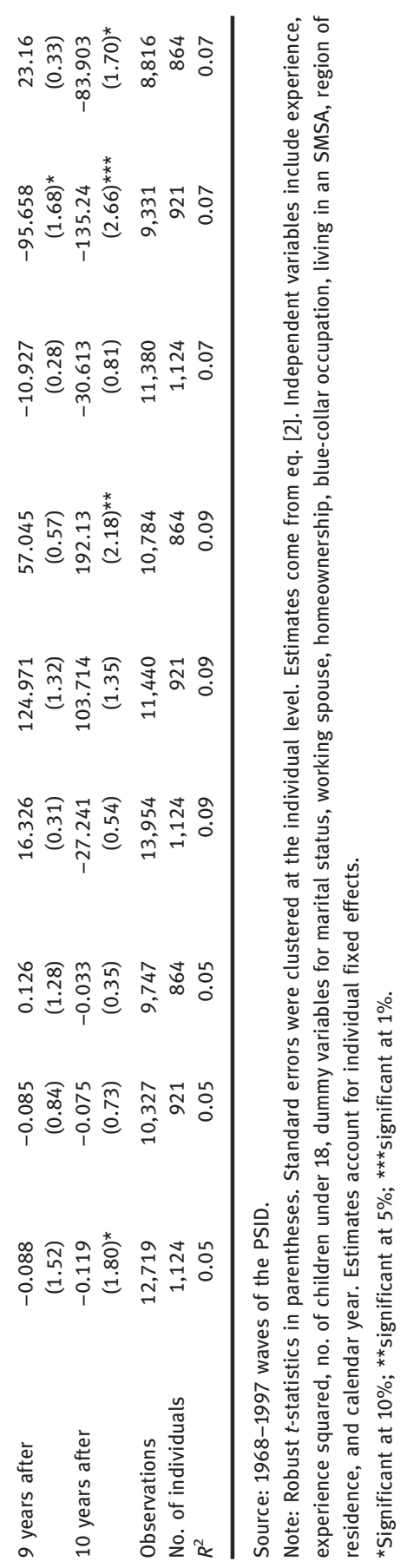


consumption are important for understanding how earnings shocks alter economic well-being. The permanent income hypothesis states that households can smooth their consumption in response to earnings shocks, and the amount of smoothing is dependent upon the permanence of the shock. Furthermore, Stephens (2002) and Jolly (2013) show that a spouse's earnings can mitigate the earnings losses associated with a husband's job displacement. Therefore, examining both earnings and consumption responses to displacement provides a more complete analysis of how job loss alters economic well-being. Since this paper's focus is on migration and displacement, this analysis focuses on the probability of homeownership as an alternative form of consumption.

To see how displacement affects the probability of homeownership, a version of eq. [1] was estimated using the entire sample of displaced and non-displaced workers. Specifically, the following was estimated $y_{i t}=x_{i t}^{\prime} \beta+\sum_{k \geq-2} D_{i s}^{k} \delta_{k}+\gamma_{t}+\alpha_{i}+\varepsilon_{i t}$, where all variables are defined as before (this equation is standard when estimating the costs of displacement). However, $y_{i t}$ equals 1 if the person was a homeowner in period $t$ and 0 otherwise. To conserve on space, the results are discussed only and are available upon request. All of the displacement dummy variables from one year before separation to 10 years afterward are statistically insignificant. This finding indicates that displacement has no statistically significant impact on the probability of homeownership. It is important to keep in mind that this result does not imply that displacement does not affect other forms of housing consumption. For example, displaced homeowners may try to reduce their mortgage payments in different ways. Additionally, displaced renters may move to a new apartment in order to reduce rental payments. This would be an interesting area of future research.

While displacement may not directly affect the probability of homeownership, mobile displaced workers may have different homeownership probabilities after migration from those who do not move shortly after job loss occurs. Table 5 presents estimates of mobility's potential impact on the probability of homeownership from eq. [2], which is something that the earlier literature has not considered. Results indicate that mobile displaced workers experience a reduction in the probability of homeownership starting the year of migration when compared to the non-mobile. The reduced probability is short-lived. Starting 4 years after migration, the estimates are statistically insignificant, indicating that mobile displaced workers face the same probability of homeownership when compared to those who do not move within a short time after job loss occurs. The reason for moving seems to matter. Those migrating for job-related reasons face a statistically significant reduced probability of homeownership during the year after migration. The effect is still short-lived, lasting only until the third 
Table 5: Migration's potential impact on homeownership by mobility status.

\begin{tabular}{lcc}
\hline & Mobile & Job-related mobile \\
\hline Year of & -0.12 & -0.05 \\
& $(6.04)^{\star \star \star}$ & $(1.03)$ \\
1 year after & -0.14 & -0.29 \\
& $(6.67)^{\star \star \star}$ & $(6.13)^{\star \star \star}$ \\
2 years after & -0.09 & -0.22 \\
& $(4.30)^{\star \star \star}$ & $(4.12)^{\star \star \star}$ \\
3 years after & -0.06 & -0.14 \\
& $(2.96)^{\star \star \star}$ & $(2.63)^{\star \star \star}$ \\
4 years after & -0.03 & -0.05 \\
& $(1.46)$ & $(1.12)$ \\
5 years after & -0.02 & -0.03 \\
& $(1.20)$ & $(0.58)$ \\
6 years after & -0.01 & -0.04 \\
7 years after & $(0.62)$ & $(0.93)$ \\
& -0.01 & -0.05 \\
y years after & $(0.28)$ & $(1.13)$ \\
& 0.01 & -0.08 \\
9 years after & $(0.55)$ & $(1.95)^{\star}$ \\
10 years after & -0.01 & -0.06 \\
& $(0.52)$ & $(1.48)$ \\
Observations & -0.01 & -0.01 \\
$R^{2}$ & $(0.75)$ & $(0.29)$ \\
\hline
\end{tabular}

Source: 1968-1997 waves of the PSID.

Note: Robust $t$-statistics in parentheses. Standard errors were clustered at the individual level. Estimates come from eq. [2]. Dependent variable is homeownership. Independent variables include experience, experience squared, no. of children under 18, dummy variables for marital status, working spouse, blue-collar occupation, living in an SMSA, region of residence, and calendar year. Estimates account for individual fixed effects.

*Significant at $10 \%$; ** significant at $5 \%$; *** significant at $1 \%$.

year afterward. However, when compared to all mobile displaced workers, the statistically significant estimates for those moving for job-related reasons are more than double. These results suggest that migrating displaced workers may decide to rent while they acquire more information on their new location of residence. They decide to purchase homes only after developing some locationspecific capital. 


\section{Conclusions}

The purpose of this paper is to analyze how the costs of job displacement vary by a worker's post-separation migration status. The previous literature has used cross-sectional data, panel data on younger individuals, or panel data from Sweden. The analysis presented here uses data from the 1968 through 1997 survey waves of the Panel Study of Income Dynamics and focuses on those workers between 25 and 62 years old. Results from the analysis show that the costs of job displacement are not equal between mobile and non-mobile displaced workers. Those who move within the first 2 years following job loss experience lower earnings losses, fewer lost hours worked, and less time unemployed when compared to their non-mobile counterparts. The results are more pronounced for those who move for job-related reasons.

When focusing specifically on how earnings, hours worked, and hours unemployed vary over time around the date of the first post-displacement move, results show that earnings increase significantly from the second year after migration until around the seventh year afterward. There is a more persistent increase in hours worked and a long-term reduction in time spent unemployed. The earlier literature has ignored migration's potential effect on the probability of homeownership. This study finds that individuals who move after displacement experience a short-term reduction in the probability of owning a home.

These results should aid in the understanding of an important adjustment mechanism available for displaced workers. The analysis does not account for whether workers find reemployment before or after migration, and knowing the order of events could shed light on some potentially important differences in workers' adjustment processes. However, results from the analysis still indicate that extending the job search geographically (with reemployment occurring before or after the move) can aid in workers' recovery from displacement. Additionally, the estimated equations and various sensitivity checks attempt to account for self-selection into migration. Any remaining selectivity not accounted for will bias the results and make identifying a causal effect of migration on various post-displacement outcomes difficult. However, the estimated equations used here are common in the literature and still identify an important association between geographic mobility and earnings, hours worked, and time unemployed. Policies designed to assist dislocated workers should consider the potential benefits of geographic migration. Furthermore, those policies already in existence, such as Job Search and Relocation Allowances from TAA, are potentially justified given the results presented here. Exploring how the order of events (i.e., finding reemployment before or after migration) affects displaced workers' outcomes would be an interesting area for future research. 


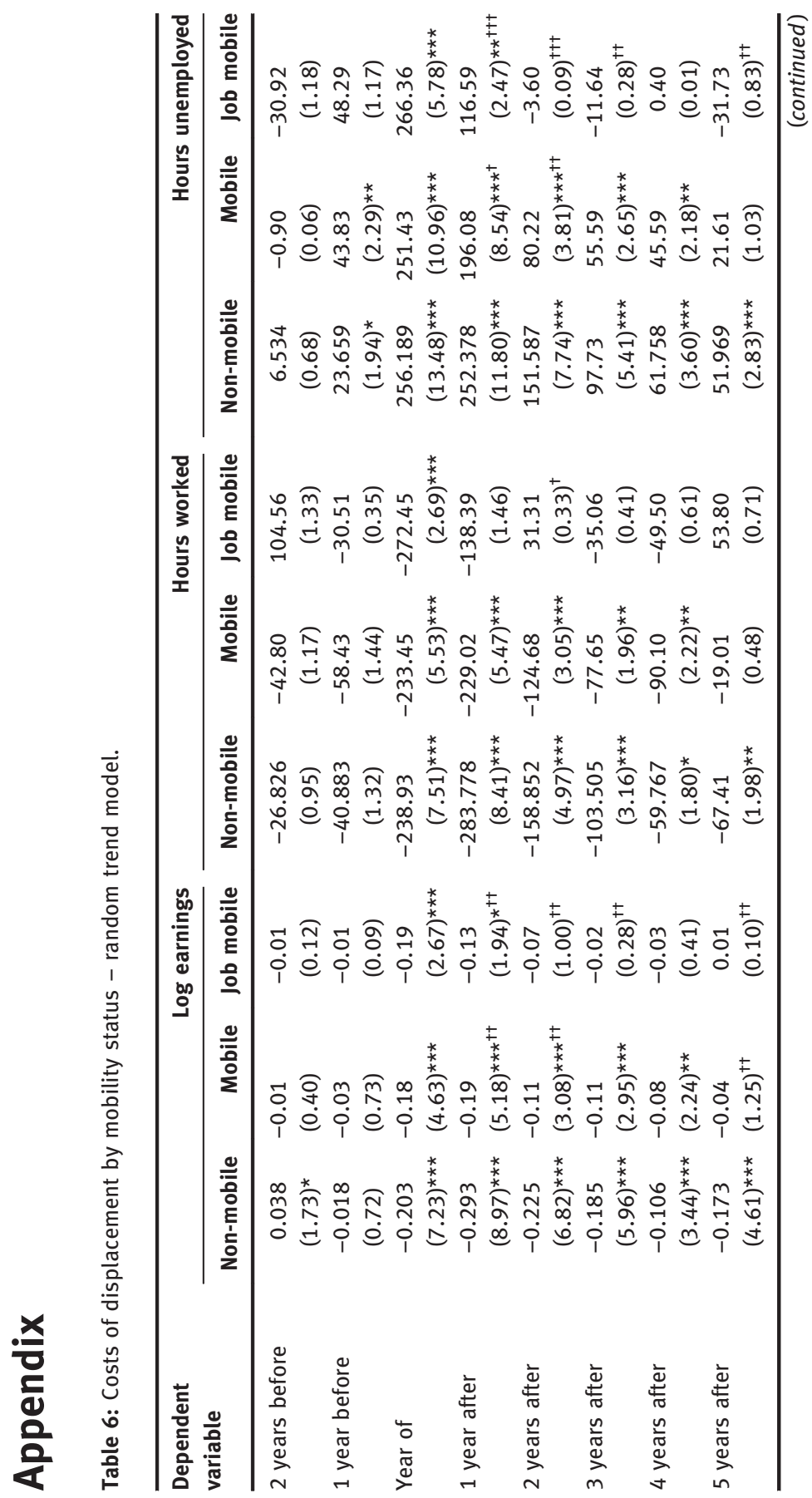




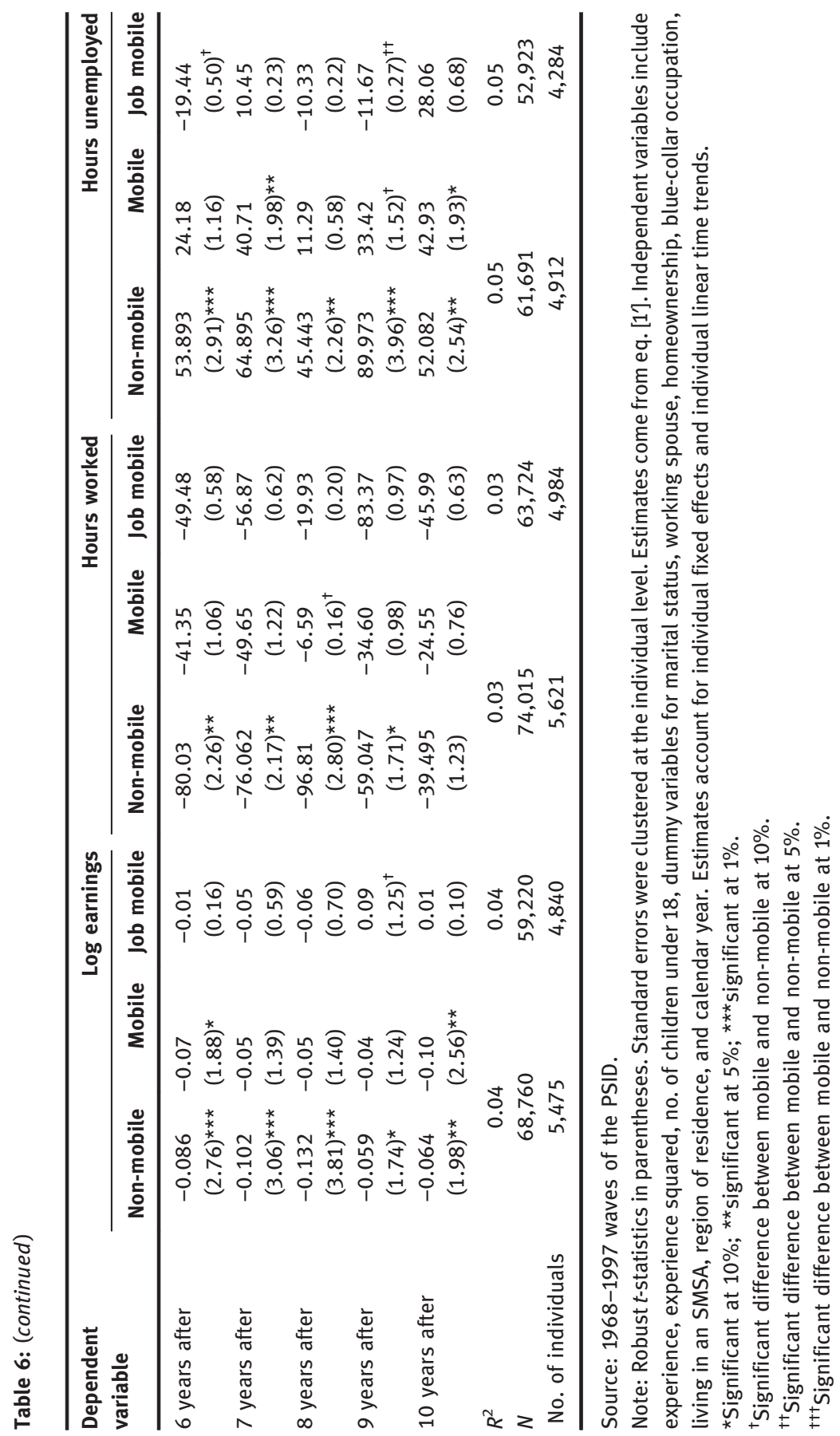




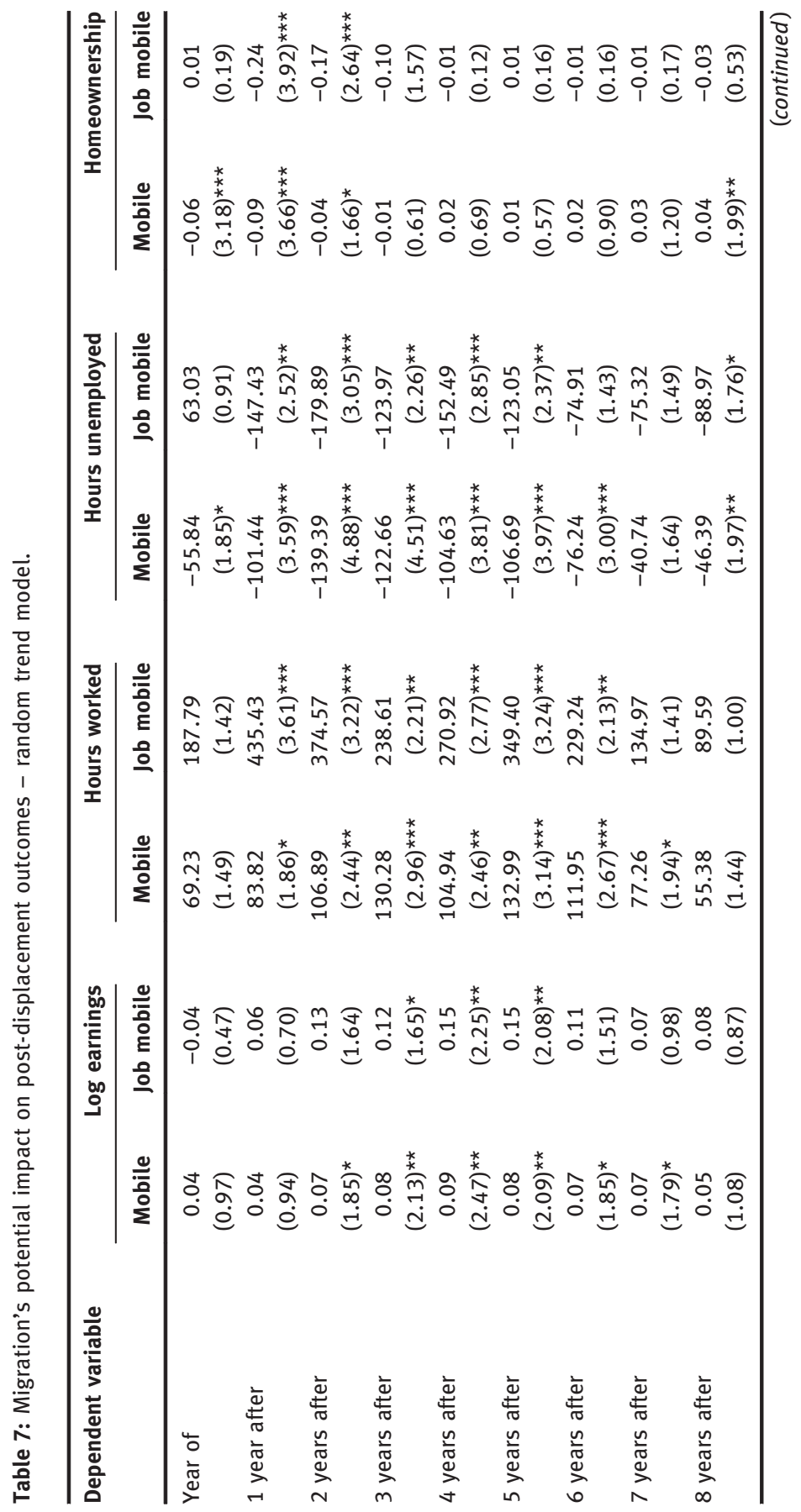




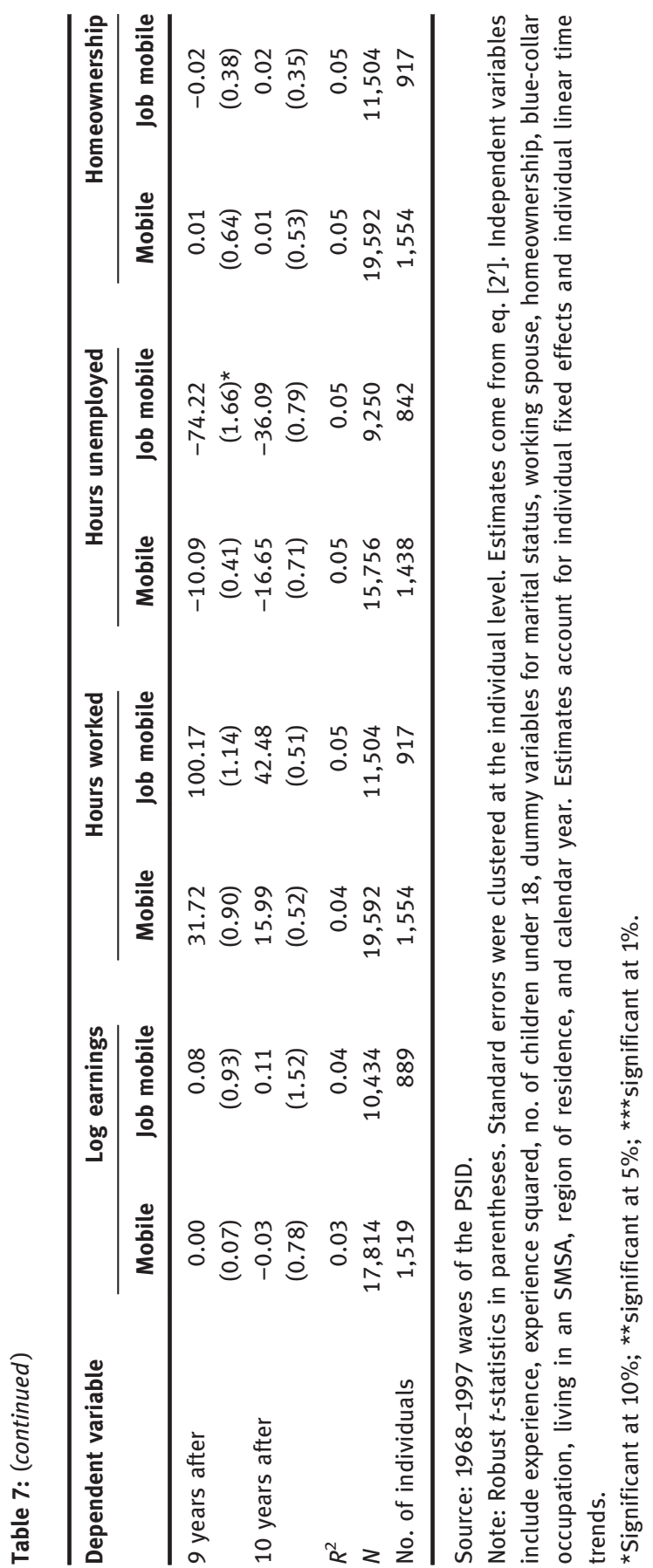




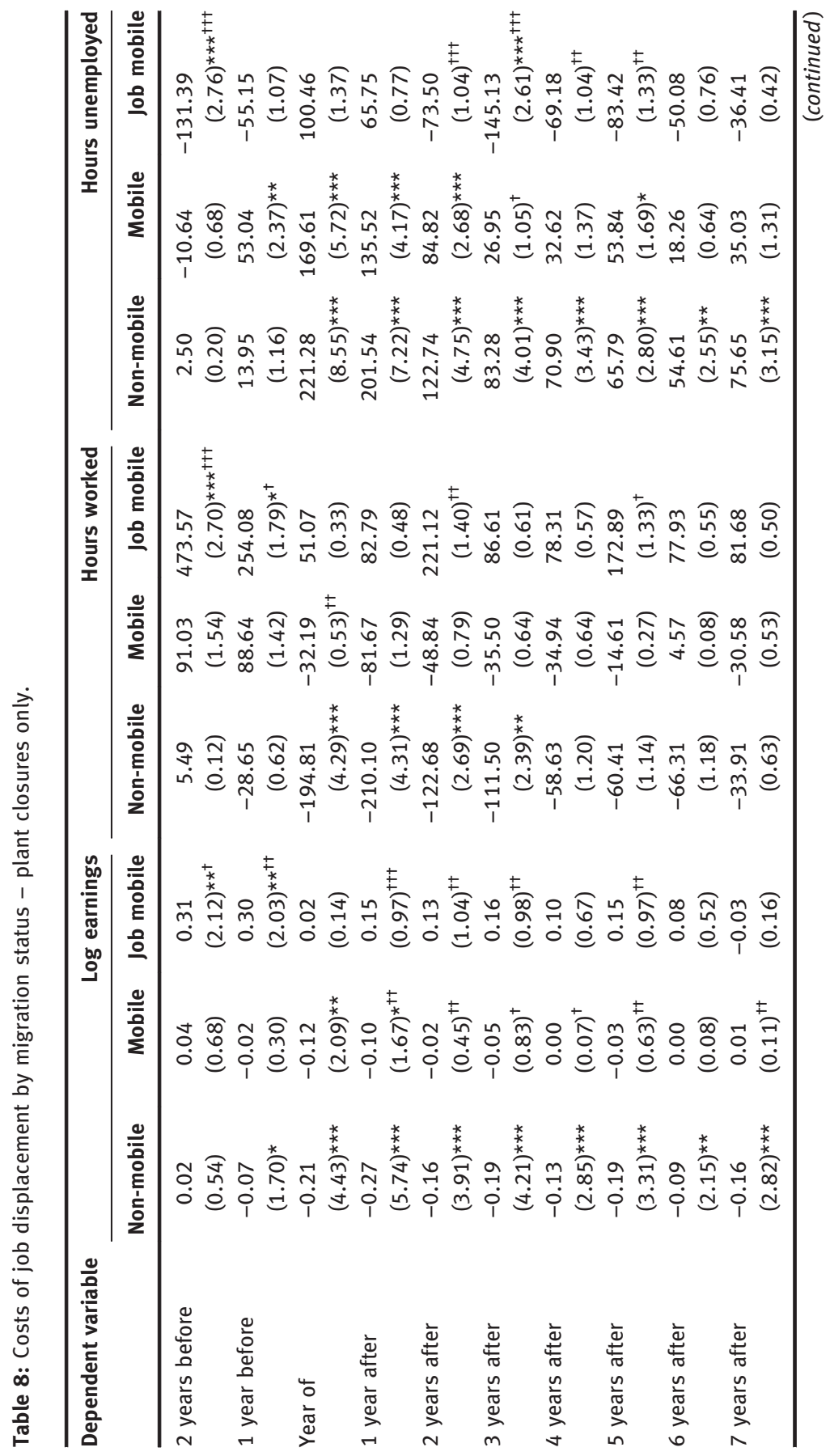




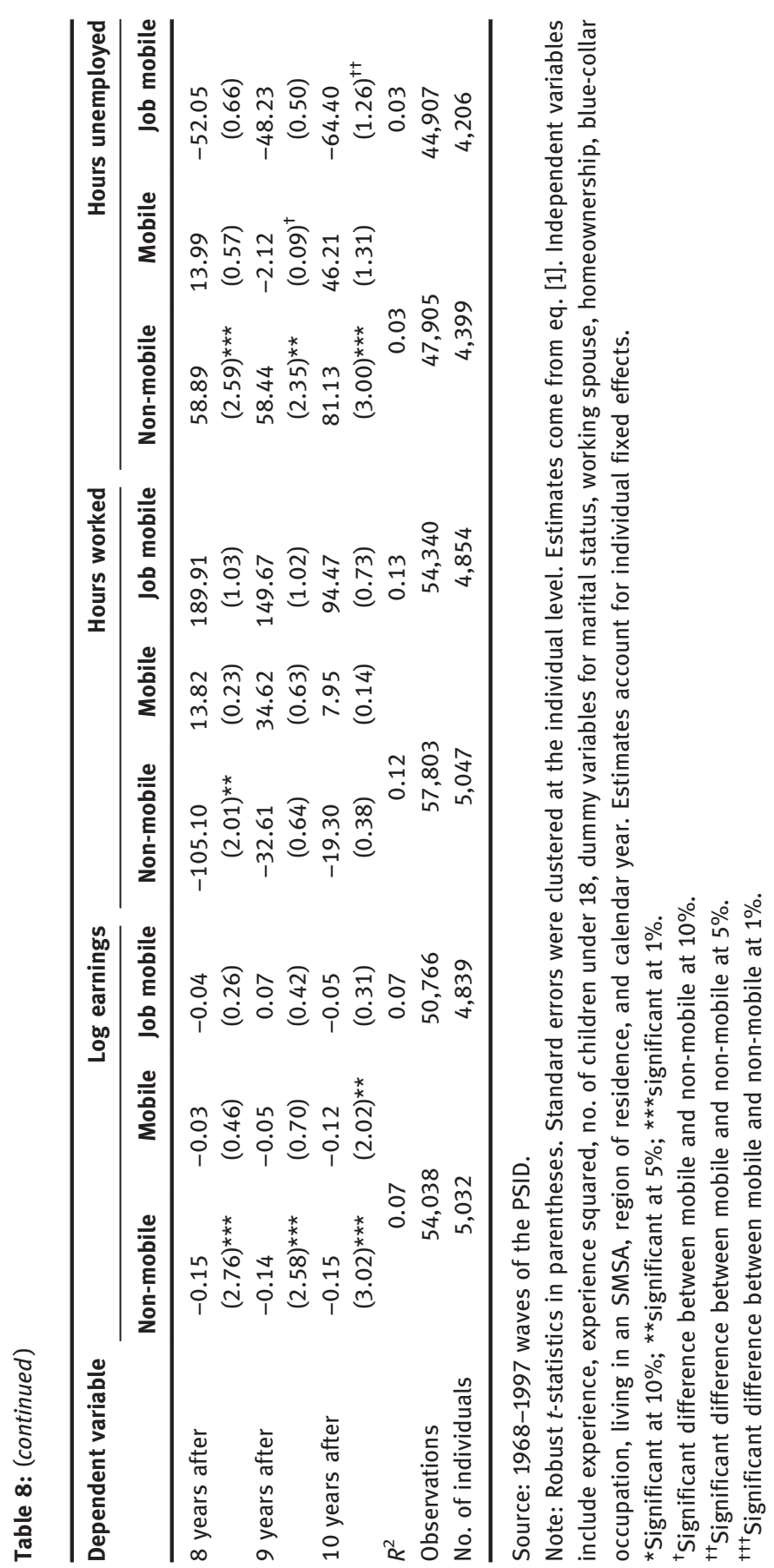




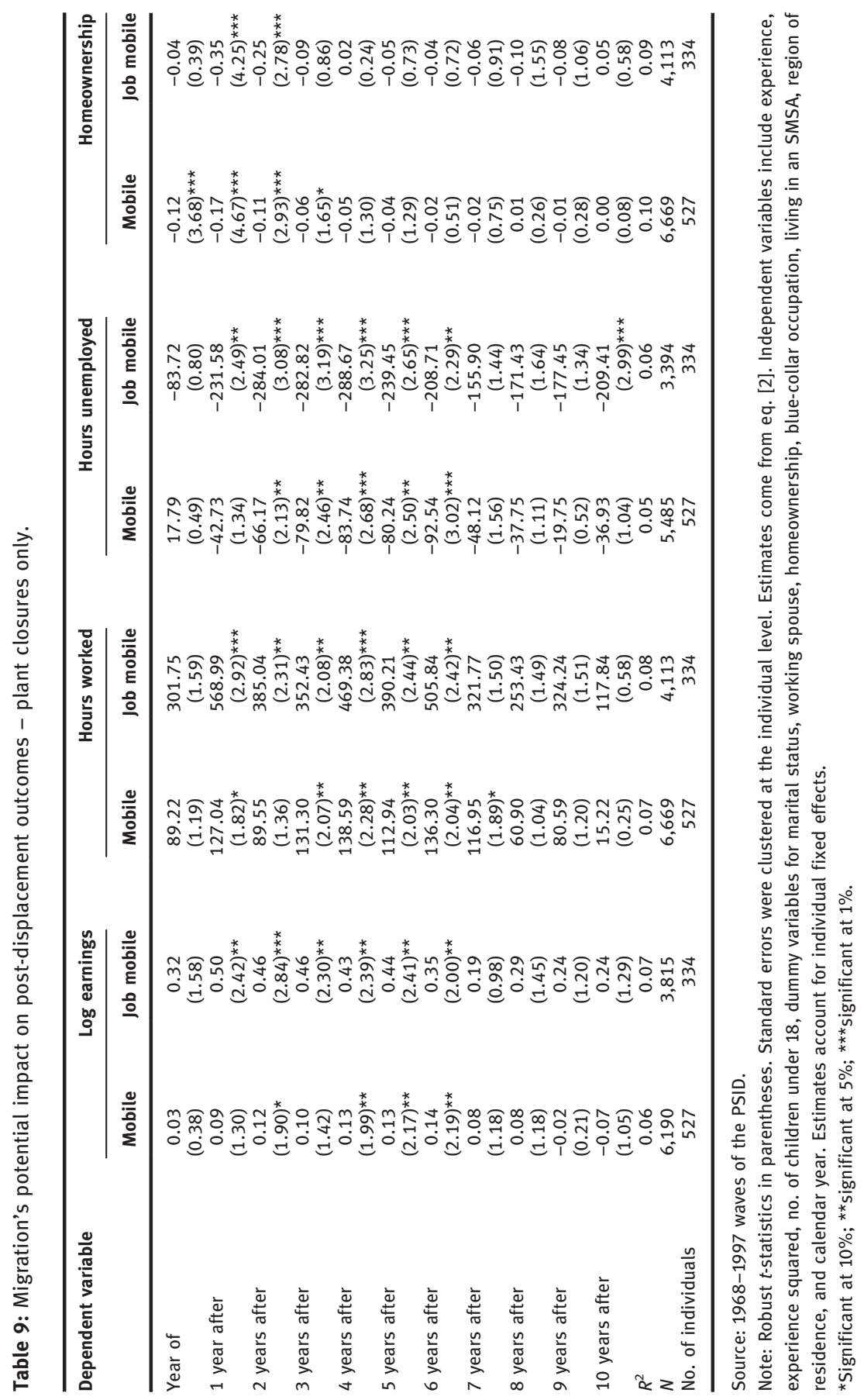


Table 10: Results from test of self-selection into migration.

\begin{tabular}{lrrr}
\hline & Log earnings & Hours worked & Hours unemployed \\
\hline Eventual mobile & -0.062 & 46.453 & -10.170 \\
displaced worker & $(1.19)$ & $(0.92)$ & $(0.52)$ \\
$R^{2}$ & 0.20 & 0.10 & 0.09 \\
$N$ & 811 & 826 & 826 \\
\hline
\end{tabular}

Source: 1968-1997 waves of the PSID.

Note: Robust $t$-statistics in parentheses. Estimates come from eq. [3]. Additional independent variables include experience, experience squared, no. of children under 18, dummy variables for marital status, working spouse, homeownership, blue-collar occupation, living in an SMSA, region of residence, and calendar year.

\section{References}

Addison, J. T., and P. Portugal. 1987. "The Effect of Advance Notification of Plant Closings on Unemployment.” Industrial and Labor Relations Review 41 (1):3-16.

Boman, A. 2011. "Does Migration Pay? Earnings Effects of Geographic Mobility Following Job Displacement." Journal of Population Economics 24 (4):1369-84.

Carrington, W. J. 1993. "Wage Losses for Displaced Workers: Is It Really the Firm That Matters?" The Journal of Human Resources 28 (3):435-62.

Cooke, T. J., P. Boyle, K. Couch, and P. Feijten. 2009. "A Longitudinal Analysis of Family Migration and the Gender Pay Gap in Earnings in the United States and Great Britain." Demography 46 (1):147-67.

Couch, K. A., N. A. Jolly, and D. W. Placzek. 2011. "Earnings Losses of Displaced Workers and the Business Cycle: An Analysis with Administrative Data." Economics Letters 111 (1):16-19.

Couch, K. A., and D. W. Placzek. 2010. "Earnings Losses of Displaced Workers Revisited." American Economic Review 100 (1):572-89.

Fallick, B. C. 1996. "A Review of the Recent Empirical Literature on Displaced Workers." Industrial and Labor Relations Review 50 (1):5-16.

Fitzgerald, J., P. Gottschalk, and R. Moffitt. 1998. “An Analysis of Sample Attrition in Panel Data: The Michigan Panel Study of Income Dynamics." The Journal of Human Resources 33 (2):251-99.

Gabriel, P. E., and S. Schmitz. 1995. "Favorable Self-Selection and the Internal Migration of Young White Males in the United States." The Journal of Human Resources 30 (3):460-71.

Gibbons, R., and L. F. Katz. 1991. "Layoffs and Lemons." Journal of Labor Economics 9 (4):351-80.

Gustafson, C. K. 1998. “Job Displacement and Mobility of Younger Workers.” Center for Labor Economics. University of California, Berkeley: Working Paper No. 8.

Herzog, H. W., and A. M. Schlottmann. 1995. "Worker Displacement and Job-Search: A Regional Analysis of Structural Impediments to Reemployment." Journal of Regional Science 35 (4):553-77. 
Jacobson, L. S., R. J. LaLonde, and D. G. Sullivan. 1993. "Earnings Losses of Displaced Workers." The American Economic Review 83 (4):685-709.

Jolly, N. A. 2013. "Job Displacement and the Intertemporal Movement of Workers through the Earnings and Income Distributions." Contemporary Economic Policy 31 (2):392-406.

Lindo, J. M. 2010. "Are Children Really Inferior Goods? Evidence from Displacement-Driven Income Shocks." The Journal of Human Resources 45 (2):301-27.

Neal, D. 1995. "Industry-Specific Human Capital: Evidence From Displaced Workers." Journal of Labor Economics 13 (4):653-77.

Nord, S., and Y. Ting. 1991. "The Impact of Advance Notice of Plant Closings on Earnings and the Probability of Unemployment." Industrial and Labor Relations Review 44 (4):681-91.

Nord, S., and Y. Ting. 1992. "The Impact of Advance Notice: A Rejoinder." Industrial and Labor Relations Review 45 (4):674-82.

Panel Study of Income Dynamics. 2004. public use dataset. Produced and distributed by the Institute for Social Research, Survey Research Center, University of Michigan, Ann Arbor, MI (1968-1997).

Pekkala, S. 2002. “Migration and Individual Earnings in Finland: A Regional Perspective." Regional Studies 36 (1):13-24.

Rodgers, J. R., and J. L. Rodgers. 2000. "The Effect of Geographic Mobility on Male Labor-Force Participants in the United States." Journal of Labor Research 21 (1):117-32.

Ruhm, C. J. 1991. "Are Workers Permanently Scarred by Job Displacements?.” The American Economic Review 81 (1):319-24.

Stephens, M. 2001. "The Long-Run Consumption Effects of Earnings Shocks." The Review of Economics and Statistics 83 (1):28-36.

Stephens, M. 2002. "Worker Displacement and the Added Worker Effect." Journal of Labor Economics 20 (3):504-37.

Stevens, A. H. 1997. "Persistent Effects of Job Displacement: The Importance of Multiple Job Losses." Journal of Labor Economics 15 (1):165-88.

US Department of Labor. TAA Program Benefits and Services under the 2011 Amendments (Current Law). Accessed August 2013. http://www.doleta.gov/tradeact/2011_amend_att1. cfm.

Yankow, J. J. 2004. "The Geographic Mobility of Displaced Workers: Do Local Employment Conditions Matter?" The Review of Regional Studies 34 (2):120-36. 